\title{
Aproximação de João Cabral
}

\author{
Jean Pierre Chauvin* \\ Escola de Comunicações e Artes da Universidade de São Paulo \\ * Autor para correspondência: tupiano@usp.br
}

\section{RESUMO}

Neste artigo, discutem-se modos de analisar e interpretar a poesia de João Cabral de Melo Neto (1920-1999). As reflexões respaldam-se na fortuna crítica e envolvem experiências na preparação dos conteúdos formais e sua discussão em sala de aula. Trata-se de versos a veicular poderosas metáforas, escoradas em sintaxe econômica, e cuja sonoridade é reforçada por aliterações. Elementos recorrentes em sua obra - a exemplo do rio, da pedra e da luz - demandam leitura atenta e cerebrina, o que não impede ao leitor experimentar agradáveis sensações, simultaneamente ao que a poesia diz, sugere e ensina.

Palavras-chave: Poesia Brasileira; João Cabral de Melo Neto; Crítica; Ensino.

\begin{abstract}
In this article, we discuss some ways of analyzing and to interpretate João Cabral de Melo Neto's poetry (19201999). These reflections are based on a critical fortune and involve experiences in the preparation of formal contents and their discussion in the classroom. These verses are a shelter to powerful metaphors, espoused in economic syntax, whose sonority is reinforced by alliterations. Recurring elements in his work - like the river, the stone and the light - demand an attentive and cerebral reading, which doesn't prevent the reader from experiencing pleasant sensations, simultaneously to what poetry says, suggests and teaches.
\end{abstract}

Keywords: Brazilian Poetry; João Cabral de Melo Neto; Criticism; Teaching.

As steady'as I can wish that my thoughts were,

Smooth as thy mistress' glass, or what shines there,

The sea is now; and, as the isles which we

Seek, when we can move, our ships rooted be

John Donne ${ }^{1}$

Simplesmente lhe digo que me olhei num espelho e não me vi. Não vi nada.

Só o campo, liso, às vácuas, aberto como o sol, água limpíssima, à dispersão da luz

João Guimarães Rosa ${ }^{2}$

Um canavial tem a extensão

ante a qual todo metro é vão

João Cabral de Melo Neto ${ }^{3}$

\section{Aula}

O que se vai ler é, em síntese, a versão parcial do discurso que preside as aulas sobre João
Cabral de Melo Neto (1920-1999), com ênfase em sua vasta produção poética. Redigido sob a forma ensaística, o texto tenta reproduzir ordenadamente os momentos praticados em sala, como fruto da preparação das aulas e da convivência com os alunos que cursam a disciplina Cultura e Literatura Brasileira: República - ministrada na Escola de Comunicações e Artes da USP, desde $2014^{4}$.

Apresentado o tema, tratemos de sua disposição. 1. As aulas em questão dividem-se em cinco etapas. Na primeira, este professor compartilha, com os alunos, material impresso que contém dez poemas de João Cabral. A ideia é favorecer o contato inicial dos estudantes com os versos. A seleção abrange livros publicados em etapas distantes da carreira do poeta.

2. Disponibilizados os textos, o professor resume e comenta alguns lances biográficos do escritor e diplomata pernambucano para, em seguida, 
discutir as fases em que a sua obra costuma ser dividida, segundo os historiadores e críticos literários. Nessa ocasião, o professor entrega alguns ensaios críticos, que circulam na sala.

3. Dirimidas as questões iniciais, relativas à carreira do poeta, e discutidos alguns conceitos que caracterizam a sua produção, passa-se à leitura dos textos. Nesse momento, solicita-se aos alunos que se revezem, espontaneamente, na declamação dos versos recebidos, orientando-os, conforme o caso, a enfatizarem modos alternativos de ler poesia - o que envolve ritmo de leitura, entonação, cesura etc.

3. 1. Para ilustrar outros modos de apreender o que o texto diz, o professor compartilha com os estudantes a releitura de alguns excertos, com vistas a ressignificar determinadas imagens e temas, recorrentes nos versos cabralinos. A análise recai sobre os aspectos formais (gêneros poéticos), estilísticos, semânticos, sintáticos, gráficos e sonoros, sugeridos pelos textos.

4. Por se tratar de uma escrita prenhe de conceitos e metáforas sutis, os poemas costumam ser retomados, de maneira a esclarecer o sentido de passagens cuja compreensão não seja simples ou imediata. Nesse sentido, à medida que os estudantes se alternam na leitura dos versos, o professor relaciona palavras no quadro (lousa), que acumulam sentidos e estabelecem relações, por vezes, distantes.

5. O contato com a poesia cabralina demanda retrabalho. Uma das razões é que seus versos costumam contrariar os lugares-comuns e desafiam a sensibilidade e inteligência do leitor, como o próprio escritor confessou em mais de uma ocasião. Tendo lido, anotado, analisado e interpretado os poemas sob a mediação do professor, os alunos são convidados a comentar o que entenderam, de maneira a apontarem relações entre o gênero literário, o tema abordado e os recursos linguísticos empregados pelo poeta.

Este artigo tem em vista resgatar algumas dentre as valiosas contribuições de especialistas que colaboraram, efetivamente, na decifração (e apreciação) da poesia cabralina. O propósito desta aproximação é didático, o que implica o emprego de linguagem menos rebuscada, sem que se comprometam o fórum da escrita e o ambiente em que o texto venha a circular.

O fato de se tratar de uma revista acadêmica voltada ao ensino na graduação sugere que o texto possa atrair - como matéria, amparo da crítica e método de abordagem - professores, alunos e demais interessados em se (re)aproximarem da poesia. A eleição de João Cabral parece recomendável, especialmente porque a sua obra está repleta de belas imagens (ou metáforas), cuja compreensão nem sempre é evidente.

Como forma de encaminhar a exposição, a seguir, pretende-se mapear alguns dos temas recorrentes na produção cabralina. Razão segundo a qual o artigo busca alternar a análise mais detida dos poemas com a intervenção de diversos críticos que se debruçaram, com inteligência e acerto, sobre a obra do escritor.

\section{Partida}

Em depoimento a Décio Pignatari, João Guimarães Rosa afirmava que a ficção brasileira produzida em seu tempo era "muito frouxa: [...] quase metade de toda e qualquer prosa escrita no Brasil é feita de vogais". Quer dizer, mesmo quando pretendia representar a fala em esporas e o ato bravio dos jagunços - em simbiose com a paisagem sertaneja -, as palavras sugeriam "uma prosa que não tem [tinha] caráter" (PIGNATARI, 2011, p. 33).

Objetivando obter maior sonoridade, o autor de Grande Sertão: Veredas recorria a uma quantidade inusual de consoantes (a exemplo do "r", do "s" e do "t"), com que criava uma "prosa pedregosa" (Idem, ibidem). Cumpre observar que, para além do maior impacto sonoro, o procedimento rosiano pode ter reforçado o ethos de suas personagens e conferido maior concretude aos ambientes em que elas se moviam. Tudo isso sem comprometer a verossimilhança do texto ficcional (pelo contrário, a linguagem "pedregosa" de Guimarães Rosa traduz com aparente fidedignidade a fala recortada do sertanejo e exprime as constantes disputas verbais entre os líderes dos bandos, no sertão de Minas). 
Algo análogo aconteceu no âmbito da poesia Numa entrevista para a televisão, durante a década de $1970^{5}$ (QUATRO, 2007), João Cabral de Melo Neto defendia a hipótese de que os seus versos tinham propósito sensorial, estimulados pelo efeito de concretude e aspereza. Por isso mesmo, era "uma poesia difícil de ser lida em voz alta". Avesso ao embalo rítmico, ao "automatismo dos sonetos decassílabos" - que lera compulsoriamente nos tempos de escola -, para o poeta, fazer versos não constituía trabalho espontâneo, que brotasse conforme o maior ou menor lunatismo ou inspiração do sujeito.

É que, para Cabral, fazer poesia era fruto de arte rigorosa, submetida a várias camadas de (re) escrita, até que o verso chegasse à forma mais econômica possível e não ressoasse "liso" - o que caracterizava os poetas líricos de outrora - mas rugoso. "Não uma poesia como se fosse um carro deslizando em cima de um pavimento de asfalto - aquela coisa lisa. Eu gostaria de fazer uma poesia na qual o leitor (no caso, identificado ao carro) passasse em cima de uma rua muito mal calçada" (MELO NETO, s/d). De acordo com Maria Lúcia Pinheiro Sampaio:

Como nos diz Jean Cohen, a metáfora não é o desvio, mas surge da redução deste. A norma e a redução do desvio se situam no plano paradigmático, ao passo que o desvio em si está no plano sintagmático. A impertinência de sentido criada pela metáfora é uma violação do código, que resolve esse impasse reduzindo a impertinência e se reestruturando (SAMPAIO, 1978, p. 9).

Resumidamente, sua poética estabelecia constantes relações entre o concreto e o abstrato, refletidas no diálogo entre o objeto - cru, por vezes reduzido ao menor significante possível - e sua projeção na forma de poderosas metáforas - potencialização imagética sugerida pelas distantes relações entre os termos. É curioso que seus versos estimulem numerosas análises e dizeres, já que foram concebidos "racionalmente" ${ }^{6}$ e em apologia metrificada do "antilirismo"?
Duradoura e multifacetada, a obra cabralina tem sido lida sob várias perspectivas - literária, sociológica, filosófica, psicológica e histórica -, o que sugere, por si só, a extensão e o alcance de seus versos. Vale lembrar que o poeta chamou a atenção de Antonio Candido (1943) desde cedo, com Pedra do Sono ${ }^{8}$. Não é de se espantar que ensaístas de grande talento tenham se dedicado à sua obra, especialmente a partir da década de 1970. Daí a reverberação de uma poesia que questionava os temas, as convenções e o "transbordamento" de estéticas anteriores.

João Cabral escrevia para o leitor em tom de desafio, o que implicava o caráter didático de sua composição. O paradoxo (dificuldade/didatismo) é aparente. Tratava-se, não apenas, de uma poesia a ser fruída, mas que suscitasse o raciocínio do leitor, exposto às imagens embutidas palavra a palavra: "depois de um Drummond, um Murilo, tentei fazer uma poesia construída, sem a espontaneidade do modernismo" (MELO NETO, 1996, p. 26).

Outro aspecto relevante estava em sobrepujar o elemento puramente referencial. Na poesia cabralina, o ambiente pode se transformar em personagem, na forma da pedra que leciona silêncios, ou do rio solidário às populações ribeirinhas. Como afirmou Haroldo de Campos, o poeta afere "categoria estética a muito daquilo que, no chamado romance nordestino, tinha apenas categoria documentária" (CAMPOS, 1967, p. 72). De certa maneira, ao desnudar o que era a matéria do poema, aplicando a ela o seu método racional de composição, João Cabral convertia o fazer poético em lição autoexplicativa.

Nesse sentido, tomar contato com os seus versos é experiência irrepetível e pode se constituir em método eficaz de aprimorar nossa leitura. Diante da poesia cabralina, constatamos que determinados temas, personagens, campos semânticos e limites do gênero logram outro estatuto, para além da obsessão pelos dados biográficos ou pelas definições reproduzidas periodicamente em manuais de literatura.

\section{Chegada}

Esses dados podem ser muito produtivos. Afinal, estamos a tratar de um de nossos maiores 
representantes literários do século XX. Isto posto, digamos que para escrever sobre João Cabral seja preciso: considerar as singularidades da sua poesia; resgatar a afinidade do poeta com as estéticas de vanguarda; destacar a representação, ou mesmo a antropomorfização da paisagem (seja ela pernambucana ou sevilhana); enfatizar os aspectos semânticos, sonoros e imagéticos sintetizados pela palavra.

No reboque de seus versos, a palavra é coisa, essência, substância. Compreendida como matéria, ela tem aroma, dimensão, cor, aspecto e peso. Núcleo referente, significante e de significado, a palavra se amplifica, graças à "acumulação semântica" - como sugeriram os poetas concretistas, em mais de uma ocasião. Disso decorre a reunião de "linguagem direta, economia e arquitetura funcional do verso" (CAMPOS, PIGNATARI \& CAMPOS, 2006, p. 216).

Acresce que, sem ser propriamente um editor, João Cabral também imprimiu livros, maiormente os de seus amigos ${ }^{9}$, sob o selo de nome sugestivo: O Livro Inconsútil. Solange Rebuzzi ressalta que "o poeta reconhecia [...] que escrever era também se envolver com a fabricação do livro, com a escolha do papel e com as letras (o tipo etc.) tanto quanto com o texto" (REBUZZI, 2010, p. 99). Também por isso, a aparente dureza (ou crueza) da palavra não a emudece, nem a congela inerme, em estágio de suspensão, modos de frieza ou morte.

Na poesia cabralina, a palavra/essência é tão ou mais importante que as relações, quase sempre imprevistas, entre um termo e outro e sua disposição na página "mineral". Daí se compreende o constante uso de metáforas agudas: método basilar de sua composição. Como observou Marly da Silveira, "Às vezes o poema é gerado por um objeto [...]. De certo modo, isso é que singulariza a poesia de João Cabral de Melo Neto na poesia brasileira e faz dele um inventor, na acepção poundiana, pois refoge o explicitamente confessional e faz da imagem o núcleo do poema" (SILVEIRA, 1999, p. 20).

Reiteremos: em João Cabral, é a palavra que está em questão. O poeta estava interessado em objetificar o poema; síntese em lugar de extravasamento: "palavra é coisa" (QUATRO, 2007). Antonio Carlos Secchin descreveu esse procedimento racionalista como "desativação onírica". Ou seja, uma "espécie de aguçamento da consciência poética, que irá analisar o espaço onírico para aprender, por sua superação, a investir na direção do dado concreto". (SECCHIN, 2014 , p. 44, grifos do autor).

Uma amostra disso. Quando recebeu um grupo de jornalistas na sua residência, ao final da vida, João Cabral declarou aos entrevistadores: "Isto que você vê na minha poesia de apresentar uma metáfora e depois discuti-la, associá-la a outras, negá-la de novo, reafirmá-la, isto eu aprendi com eles [poetas]. Claro que a substância das metáforas é diferente, mas a técnica eu aprendi com os metafísicos ingleses"10 (MELO NETO, 1996, p. 20).

Se, na Espanha, o poeta flertava com o trabalho de Juan Miró e dos cubistas, no Brasil, o seu diálogo mais fecundo estabelecia-se com Murilo, Drummond e Bandeira. João Cabral refere-se constantemente aos três, como se publicizasse o débito para com os amigos poetas e missivistas. Autor de versos capazes de sugerir a "captação plástica do real" (SECCHIN, 2014, p. 20), quase assusta a sua habilidade em tomar de empréstimo o estilo, o vocabulário e a expressão daqueles a quem se dirigia. Daí a estilização de Murilo, que tinha o curioso hábito de saudar os rios:
Explicação daquele rito, vinte anos depois, aqui tento: nos rios, cortejava o Rio, o que, sem lembrar, temos dentro. (MELO NETO, 2009, p. 98).

Se Murilo Mendes teria inspirado Cabral desde os primeiros versos, o diálogo com Drummond foi tão ou mais marcante e duradouro. Segundo Affonso Romano de Sant'Anna: "Não é novidade a presença ostensiva de Drummond nas obras iniciais de Cabral. Todos os seus críticos já trataram disso. As provas são evidentes e são muitas. As primeiras publicações do poeta pernambucano ressoam até parafrasicamente o mineiro" (SANT'ANNA, 
2014, p. 20). É o que se nota, por exemplo, no poema "A Carlos Drummond de Andrade":

Não há guarda-chuva

contra o tédio:

o tédio das quatro paredes, das quatro estações, dos quatro pontos cardeais.

(MELO NETO, 1999, p. 79).

Maleável, a dicção cabralina ${ }^{11}$ segue em nova direção, aderindo à voz do outro poeta. É o que se nota quando descreve a paisagem da capital pernambucana, em evidente diálogo com "Evocação do Recife", de Manuel Bandeira:

O Recife até os anos quarenta era como os dedos da aranha que iam cada dia mais longe; os dedos: as linhas de bonde. (MELO NETO, 2009, p. 42).

Alexandre Shiguehara observa que "A revelação bandeiriana e drummondiana de que a poesia não precisava ser necessariamente afetada nem sentimental, e de que podia ser tocada de uma nota algo prosaica, foi fundamental para o jovem [Cabral]" (SHIGUEHARA, 2010, p. vii). As amostras são numerosas. Em outro poema impressionante, porque tecido com os instrumentos de ofício (redigido em papel timbrado, inclusive ${ }^{12}$ ), topamos com os seguintes versos, também dirigidos a Drummond:

Eu nunca suspeitaria

Tanta roupa preta;

Tão pouco essas palavras -

Funcionárias, sem amor.

(SÜSSEKIND, 2001, p. 192).

Por ora, deixemos o ambiente burocrático e contemplemos a paisagem, como sugere o poema "Rios sem Discurso". Não se trata apenas de identificar o elemento rio, em eventual analogia com o homem, mas de traduzir a torrente de palavras, a fala desdobrada, fluida feito água, a discorrer nestes termos:
Quando um rio corta, corta-se de vez o discurso-rio de água que ele fazia; cortado, a água se quebra em pedaços, em poços de água, em água paralítica. Em situação de poço, a água equivale a uma palavra em situação dicionária: isolada, estanque no poço dela mesma, e porque assim estanque, estancada; e mais: porque assim estancada, muda, e muda porque com nenhuma comunica, porque cortou-se a sintaxe desse rio, o fio de água por que ele discorria.

(MELO NETO, 1999, pp. 350-351).

O discurso, vale lembrar, é mote recorrente na obra cabralina. Antonio Carlos Secchin percebe "relações entre discurso poético e espaço referencial", no sentido de que "o curso do rio Capibaribe será representado por um discurso que buscará na forma do objeto-rio o modelo de sua enunciação" (SECCHIN, 2014, p. 74). Ora, supondo que a linguagem nos constitua, qual seria a identidade conquistada pelo rio? Estará o elemento (rio) em conjunção ou disjunção com a representação diminuta do homem?

Para Benedito Nunes, "a palavra se transfere ao rio, ao mesmo cão sem plumas do poema anterior, que então discorre sobre o seu próprio curso, assumindo o duplo papel de agente narrativo e de objeto da narração. Já agora o percurso e o discurso do rio se fazem simultaneamente como narração" (NUNES, 1974, p. 75).

Os rios que eu encontro

vão seguindo comigo.

Rios são de água pouca, em que a água sempre está por um fio.

Cortados no verão

que faz secar todos os rios.

Rios todos com nome

e que abraço como a amigos.

Uns com nome de gente, outros com nome de bicho, uns com nome de santo, muitos só com apelido. 
Mas todos como a gente

que por aqui tenho visto:

a gente cuja vida

se interrompe quando os rios.

(MELO NETO, 1999, p. 121)

Ao aderir ao rio, que percorre sinuoso a paisagem, o eu lírico alterna perspectivas sobre a existência ("uns", "outros"; "muitos", "todos"), entre a terra e a água ${ }^{13}$, o campo e a cidade. "O grau de íntima convivência com a gente dos mangues não impede que o rio - disfarce antropomórfico [...] - lhe reconheça o anonimato, contrastado pela nomeação sistemática dos lugares e acidentes geográficos que não escapam ao seu olhar" (SHIGUEHARA, 2010, p. 35).

Rio, pedra, canavial, mar e luz são coisa, elemento e motivo. Eles constituem uma seleta do "léxico cabralino", de que nos fala Antonio Carlos Secchin (2014). João Cabral concedeu-lhes a primazia sobre muitos temas, formas e seres, incluindo o homem. É que discorrer sobre uma espécie imperfeita e previsível, como o bicho homem, porventura implicasse falar sobre si mesmo - o que não condiz com o método sonhado pelo engenheiro.

A luz, o sol, o ar livre envolvem o sonho do engenheiro.

O engenheiro sonha coisas claras:

Superfícies, tênis, um copo de água.

O lápis, o esquadro, o papel;

o desenho, o projeto, o número:

o engenheiro pensa o mundo justo,

mundo que nenhum véu encobre.

(MELO NETO, 1999, pp. 69-70).

\section{Estadia}

Afora enumerar elementos tratados sob forma artística, cumpre mencionar o aspecto mineralógico da poesia cabralina. Não esqueçamos os versos de Psicologia da Composição, em que o poeta - feito arquiteto e engenheiro - articula o ato da escrita com o suporte em branco e a qualidade do que é e pertence ao concreto, mineral:

\author{
São minerais \\ as flores e as plantas, \\ as frutas, os bichos \\ quando em estado de palavra. \\ É mineral \\ a linha do horizonte, \\ nossos nomes, essas coisas \\ feitas de palavras. \\ (MELO NETO, 1999, p. 96).
}

A palavra, que às vezes se apresenta em "situação dicionária", assume novo estatuto e muda de posição: passa a ser parâmetro da fixidez aparente que nomeia, classifica e define tudo o que é matéria - flora, fauna e o resto. João Alexandre Barbosa decifrou o método que preside o poema:

Na verdade, sendo uma "psicologia da composição", e não do poeta, é a personagem em que se transforma o poema que permite as afirmações em primeira pessoa. E uma vez aceita a ideia de que é a própria composição que diz, a sua psicologia pode ser rastreada sem que corra o risco de um enclausuramento (BARBOSA, 2008, pp. 31-32, grifos do autor).

Ler João Cabral implica lidar com procedimentos aparentemente paradoxais. É devorar com vagar uma poesia que, enxuta, demanda reflexão e parada. É tomar contato com as obras de arte a que ele alude e averiguar a hipótese de fazer da palavra mais que um conceito: objeto irredutível e matriz do poema. Em sua estética mineralógica, a palavra, entre fluida e porosa, alterna-se entre o comunicável e o indizível:

Se venta no canavial

estendido sob o sol

seu tecido inanimado

faz-se sensível lençol,

se muda em bandeira viva,

de cor verde sobre verde,

com estrelas verdes que

no verde nascem, se perdem.

Não lembra o canavial 
então, as praças vazias:

não tem, como têm as pedras,

disciplina de milícias.

É solta sua simetria:

como a das ondas na areia

ou as ondas da multidão

lutando na praça cheia.

(MELO NETO, 1999, p. 151).

Embora o escritor se declarasse refratário ao lirismo e cultivasse composições em que sobressaíam aspectos formais, o planejamento e o desejo de simetria, o leitor não estará imune aos efeitos extraordinários provocados por sua poética de um só gume. A título de ilustração, repare-se que, em "Uma faca só lâmina", o título do poema carece de ser retomado em determinadas estrofes, de modo que os blocos textuais, concebidos como elementos "cubistas", na definição de Antonio Candido (1999), adquirem pleno sentido e o poema completa seu movimento perante o leitor:

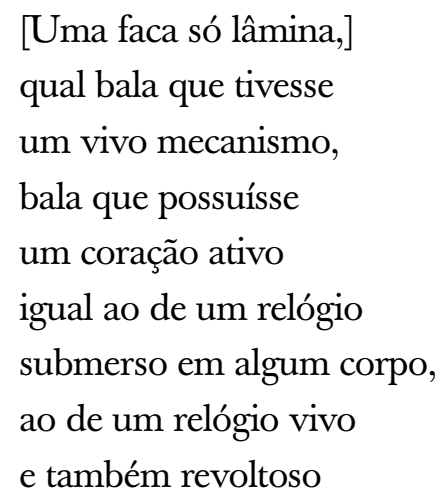

De acordo com Antonio Carlos Secchin, em "Uma faca só lâmina", "enquanto o humano é situado na morte ('um dos lados do morto'), os três termos minerais se caracterizam pela vida (bala com vivo mecanismo, faca habitando um corpo) e pela insubmissão (relógio 'também revoltoso'). A faca, desde logo, marcará diferença. É a única que traz um postulado ético: 'é toda impiedade/ de lâmina azulada"” (SECGHIN, 2014, p. 128).

É sugestivo que a maior parte de quem estuda Cabral contagie a sua análise com os modos exatos, mas curvilíneos, de sua composição. Isso porque a dicção cabralina convoca o leitor a participar ${ }^{15}$ da desmontagem e reconstrução dos sentidos. É como se a leitura metrificasse a sua compreensão.

Não se trata de nos posicionarmos, estáticos, ou estacionarmos, bestificados, diante dos versos. A poesia de João Cabral convida-nos à releitura porque não é contemplação. Os versos propõem que relacionemos elementos distantes, instaurados em poderosas metáforas. Isso não implica afirmar que se trate de uma poesia neobarroca, em função das imagens que concentra. Afinal, haverá poesia que não seja conotação, som e imagem?

O rio ora lembrava
a língua mansa de um cão,
ora o ventre triste de um cão,
ora o outro rio
de aquoso pano sujo
dos olhos de um cão.

(MELO NETO, 1999, p. 105).

Consideremos a resposta interposta por João Alexandre Barbosa, que destacou a "historicidade da poesia" cabralina, como obra vincada pelas marcas de seu tempo e lugar. Para o crítico, em "O cão sem plumas" há "imersão no Tempo, na Cidade dos homens" em que incide "a radicalização do processo de desmontagem interna do próprio poema, sobretudo através do elemento que dá origem à singularidade do poeta dentro de sua geração: o tratamento da imagem" (BARBOSA, 1975, p. 92).

João Cabral sintetizava o seu tempo e os lugares em que viveu. Não por acaso, afirmava reiteradamente que a poesia era fruto de horas vagas, durante uma longa carreira diplomática. Se levarmos em conta a sua dificuldade confessa em escrever (CASTELLO, 2006; CABRAL, 2016), talvez possamos sugerir que "dificultar" a vida do leitor espelhasse o receio do próprio poeta à autoexposição.

\section{Retorno}

Não se trata de lirismo; mas de "antilira", como definiu o próprio João Cabral, na dedicatória a Manuel Bandeira, em A Educação pela Pedra, de 1966. As estrofes, alinhadas em conteúdo, forma e 
expressão, não falam necessariamente de si, mas da concepção calculada do fazer poético, que não brota da comoção desmedida, tampouco das musas.

O verso de João Cabral é "mineral" e, sob esse aspecto, concreto. $\mathrm{O}$ poeta reconhecia seu débito para com a metáfora semeada pelos poetas metafísicos ingleses (no exemplo acabado de John Donne); preservara o diálogo com a arquitetura (Le Corbusier); a afinidade com as artes plásticas de vanguarda (Juan Miró); e admirava a expressão prosaica dos modernistas (especialmente Bandeira, Murilo e Drummond). Não por acaso, integra, ao lado de Ezra Pound, James Joyce e Oswald de Andrade, o repertório dos poetas concretistas em atividade a partir da década de 1950 .

Para se ler João Cabral de Melo Neto, há que dedicar tempo, esforço e engenho. Não é poesia que nos desmereça ou desqualifique, tampouco palavrório de ornamentação que nada implique. $\mathrm{O}$ poeta trabalhou, persistente, com conceitos e os dispôs em relação. Daí o caráter autoexplicativo de seus versos, como se vê em "A Educação pela Pedra":

Uma educação pela pedra: por lições; para aprender da pedra, frequentá-la; captar sua voz inenfática, impessoal (pela de dicção ela começa as aulas). (MELO NETO, 1999, p. 338).

A palavra entesta com a condição de "dicionária". Emancipada dos limites semânticos, é como se João Cabral concedesse maior autonomia ao verbo, sugerindo ao leitor que o conceito pode ultrapassar o uso ordinário que dele pudéssemos fazer. A pedra é capaz de ensinar, à sua maneira, o que talvez nos falte em silêncio, tempo e modos. Antonio Carlos Secchin sugere que esse poema seja "um contraponto teórico" a "O Sertanejo Falando"16.

Quanto ao rio, símbolo, forma e personagem, ele interpõe contornos na retidão e simetria das estrofes. Mais uma vez, é de identidade que se trata, como se pode ver em "O Vento no Canavial":

É anônimo o canavial, sem feições, como a campina; é como um mar sem navios, papel em branco de escrita. É como um grande lençol sem dobras e sem bainha; penugem de moça ao sol, roupa lavada estendida.

(MELO NETO, 1999, p. 150).

Distanciados pela figuração na topografia e lugar em meio à paisagem, os elementos entram em imprevisto diálogo. O canavial torna-se cúmplice do mar - aproximados não apenas devido à imagem similar que desenham, mas pelo aprendizado de que comungam (e compartilham conosco). Daí o caráter solidário de ambos os elementos, fundamentais em uma poesia que, por sua recusa ao estanque e ao óbvio, mais ensina enquanto o poeta menos discorre. João Cabral descreve e aplica aos seus versos uma autêntica didática da composição.

O que o mar sim aprende do canavial: a elocução horizontal de seu verso; a geórgica de cordel, ininterrupta, narrada em voz e silêncio paralelos. O que o canavial sim aprende do mar: o avançar em linha rasteira da onda; o espraiar-se minucioso, de líquido, alagando cova a cova onde se alonga. (MELO NETO, 1999, p. 335).

\section{Despedida}

Deve ficar claro para os alunos que, ao abordar a poesia de João Cabral, não se pode temer a forma concisa de seus versos, nem supor que essa característica faça do poema ambiente hermético, área restrita ou de difícil acesso. Sob essa perspectiva, o papel do professor pode ser decisivo. Afinal, devemse preencher eventuais lacunas de sentido - propostas como desafio, pelo poeta - com energia, lucidez e divertimento. A meta é corresponder ao pacto de leitura lançado por um versejador que forjava, de fora para dentro, feito "lição da pedra", uma arte capaz de espicaçar a curiosidade e a inquietação do leitor.

Qual o saldo da aula? Uma das principais tarefas do professor será relembrar ao aluno que 
ele não está diante de uma poesia de somenos, tampouco passatempo a enfeixar livros atirados displicentemente em consultórios ou salas de visitas. O contato com os versos cabralinos resulta no empenho do leitor.

Do pouco que se disse, depreenda-se que os poemas de qualidade não cabem em relógios ou escrivaninhas, nem disputam o espaço ordinário das contas a pagar. No caso de João Cabral, a poesia não obedece a toque(s) de recolher. É sucessão de metáforas que expandem o imaginário do leitor, ultrapassam os limites da sala e persistem como itens a decifrar, para além do espaço/tempo reservado à aula. Sigamos o poeta feito pedra, sol e rio.

\section{Notas}

1 "The Calm" ("Tão firme quanto eu poderia desejar que meus pensamentos estivessem,/ Polido como o copo da senhora, ou o que ali brilha,/ O mar está agora; E, assim como as ilhas que/ Procuramos, quando podemos nos mover, nossos navios estão ancorados").

2 ROSA, 2001, p. 126.

3 "O nada que é" (MELO NETO, 2009, p. 31).

4 A disciplina é uma herança do saudoso professor e pesquisador Ivan Prado Teixeira (1950-2013), que, entre outras coisas, colaborou ativamente da reformulação do curso de Editoração, entre 2012 e 2013. Assumi as aulas relacionadas à Colônia, Império e República, na ECA, em abril de 2014.

5 Em 1974, João Cabral de Melo Neto cedeu uma entrevista a Primeiro Plano, programa da TV Cultura de São Paulo.

6 "A minha ideia racionalista de escrever é uma coisa que eu me imponho. Eu não escrevo ambiguidades" (MELO NETO, 1996, pp. 21-22).

7 "Dedicatória" de A Educação pela Pedra (1966): "A Manuel Bandeira/ essa antilira para seus/ oitent'anos" (MELO NETO, 1999, p. 334).

8 "Esta crítica de Antonio Candido foi para mim uma revelação. Foi ela que me deu coragem de continuar escrevendo no início de minha carreira" (MELO NETO, 1996, p. 24).

9 "Nunca fui exatamente um editor. Só editei livros de amigos. Eu ia atrás deles, pedia a obra e editava. Entre o final dos anos 40 e o início da de 50, imprimi catorze trabalhos" (MELO NETO, 1996, p. 22).
10 De acordo com Inez Cabral: na década de 1950, enquanto o poeta pernambucano serviu no Consulado de Londres, "como o trabalho no consulado não deixava muito tempo livre, mergulhou na literatura e cultura inglesas, assim como no cinema clássico mundial" (CABRAL, 2016, p. 32).

11 Utilizo o conceito de "dicção", como forma de ressaltar o fato de que o eu lírico é uma persona criada pelo poeta e que não se confunde com ele. Essa distinção tem se mostrado produtiva nas aulas não exclusivamente sobre a obra de João Cabral de Melo Neto.

12 "Cabral, aprovado em concurso público, começara a trabalhar como Assistente de Seleção do Dasp (Departamento Administrativo do Serviço Público) em 1943" (SÜSSEKIND, 2001, p. 193).

13 "[...] os símbolos da Pedra e do Rio, a oposição dialética do seco e do úmido, do sol e da água, integram o patrimônio simbólico da humanidade desde a mais remota antiguidade. Já Heráclito de Éfeso afirmava que 'a harmonia da água e do fogo no organismo constitui saúde: a doença é a ruptura do equilíbrio harmonioso dos contrários" (ESCOREL, 1973, p. 53).

14 Segundo Haroldo de Campos, a poesia cabralina convida à "participação poética" por parte do leitor (CAMPOS, 1967, p. 71).

15 "Daí porque o sertanejo fala pouco:/ as palavras de pedra ulceram a boca/ e no idioma pedra se fala doloroso; / o natural desse idioma fala à força./ Daí também porque ele fala devagar:/ tem de pegar as palavras com cuidado,/ confeitá-las na língua, rebuçá-las;/ pois toma tempo todo esse trabalho" (MELO NETO, 1999, p. 336).

\section{Referências Bibliográficas}

BARBOSA, João Alexandre. A Imitação da Forma: uma Leitura de João Cabral de Melo Neto. São Paulo: Duas Cidades, 1975.

- João Cabral de Melo Neto. 2 ed. São Paulo:

Publifolha, 2008.

CABRAL, Inez. João Cabral de Melo Neto: a Literatura como Turismo. São Paulo: Alfaguara, 2016.

CAMPOS, Augusto de; PIGNATARI, Décio \& CAMPOS, Haroldo de. Teoria da Poesia Concreta: Textos Críticos e Manifestos (1950-1960). Cotia: Ateliê, 2006.

CAMPOS, Haroldo de. Metalinguagem. Petrópolis: Vozes, 1967.

CANDIDO, Antonio. "Poesia ao Norte". Revista Remate de Males. Campinas, Editora Unicamp, 1999, pp. 9-14. 
CASTELLO, José. Foão Cabral de Melo Neto: o Homem sem Alma \& Diário de Tudo. Rio de Janeiro: Bertrand, 2006.

DONNE, John. "The Calm". Disponível em: $<$ https://www.poetryfoundation.org/poets/john-donne>. Acessado em 13 jul. 2017.

ESCOREL, Lauro. A Pedra e o Rio: uma Interpretação da Poesia de foão Cabral de Melo Neto. São Paulo: Duas Cidades, 1973.

MELO NETO, João Cabral de. Cadernos de Literatura Brasileira, n. 1. São Paulo: Instituto Moreira Salles, 1996.

Nova Aguilar, 1999.

Obra completa. 3 reimp. Rio de Janeiro: Agrestes. Rio de Janeiro: Objetiva, 2009.

NUNES, Benedito. João Cabral de Melo Neto. 2 ed. Petrópolis: Vozes, 1971.

PIGNATARI, Décio. "Depoimento". In: CALLADO, Antonio et al. Depoimentos sobre foão Guimarães Rosa e sua Obra. Rio de Janeiro: Nova Fronteira, 2011, pp. 33-39.

QUATRO Vezes Quatro: Foão Cabral de Melo Neto. Documentário. TV Escola. 2007. 27'09'. Disponível em: http://tvescola.mec.gov.br/tve/video/mestres-da-lite- ratura-quatro-vezes-quatro-joao-cabral-de-melo-neto. Acessado em 13 jul. 2017.

REBUZZI, Solange. O Idioma Pedra de foão Cabral. São Paulo: Perspectiva, 2010.

ROSA, João Guimarães. "O Espelho". In: Primeiras Estórias. 15 ed. Rio de Janeiro: Nova Fronteira, 2001, pp. 119-128.

SAMPAIO, Maria Lúcia Pinheiro. Processos Retóricos na Obra de foão Cabral de Melo Neto. Assis: Ilpha; São Paulo: Hucitec, 1978.

SANT'ANNA, Affonso Romano de. Entre Drummond e Cabral. São Paulo: Editora Unesp, 2014.

SECCHIN, Antonio Carlos. Foão Cabral de Melo Neto: uma Fala só Lâmina. São Paulo: Cosac Naify, 2014.

SHIGUEHARA, Alexandre Koji. Ao Longo do Rio: João Cabral e Três Poemas do Capiberibe. São Paulo: Hedra; ECidade, 2010.

SILVEIRA, Marly da. "Prefácio". In: MELO NETO, João Cabral de. Obra Completa. 3 reimp. Rio de Janeiro: Nova Aguilar, 1999, pp. 15-24.

SÜSSEKIND, Flora. Correspondência de Cabral com Bandeira e Drummond. Rio de Janeiro: Nova Fronteira, Edições Casa de Rui Barbosa, 2001. 